\title{
Factors Influencing Nursing Students' Professional Identity in a Clinical Learning Environment in Hunan, China
}

\section{Lihong Zeng}

Xiangya Nursing School, Central South University

\section{Qirong Chen}

Xiangya Nursing School, Central South University

\section{Sisi Fan}

Hunan Labor and Human Resources Vocational College, Changsha, China

\section{Qifeng Yi}

The Third Xiangya Hospital, Central South University

\section{Wenhong An}

School of Health and Wellness,Panzhihua University

\section{Huan Liu}

Xiangya Nursing School, Central South University

\section{Wei Hua}

Xiangya Nursing School, Central South University

\section{Rong Huang}

The Third Xiangya Hospital, Central South University

Hui Huang ( $\boldsymbol{0} 852152847 @ q q . c o m$ )

The Third Xiangya Hospital, Central South University

\section{Research Article}

Keywords: Nursing Students, Clinical Learning Environment, Professional Identity, Clinical Education

Posted Date: March 11th, 2021

DOl: https://doi.org/10.21203/rs.3.rs-272707/v1

License: (c) (i) This work is licensed under a Creative Commons Attribution 4.0 International License. Read Full License 
- Title page

Title:

Factors Influencing Nursing Students' Professional Identity in a Clinical Learning Environment in Hunan, China

\section{Authors:}

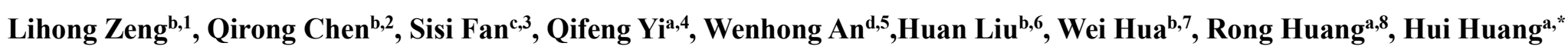

a The Third Xiangya Hospital, Central South University, Changsha, China

b Xiangya Nursing School, Central South University, Changsha, China

${ }^{C}$ Hunan Labor and Human Resources Vocational College, Changsha, China

${ }^{d}$ School of Health and Wellness,Panzhihua University, Sichuan, China

Keywords: Nursing Students; Clinical Learning Environment; Professional Identity; Clinical Education

\section{Correspondence to:}

* Corresponding author:

E-mail addresses:852152847@qq.com 


\title{
Factors Influencing Nursing Students' Professional Identity in a Clinical Learning Environment in Hunan,
}

\section{China}

\author{
Abstract \\ Background: Clinical learning environment is an important stage for nursing students, it will affect the cultivation of professional identity \\ of nursing students. This study to explore the factors influencing the cultivation of professional identity among nursing students in a clinical learning
} environment.

Methods: This was a cross-sectional study.Convenience sampling was applied to recruit 398 nursing students from The Third Xiangya Hospital of Central South University in Hunan Province. After the nursing students completed their clinical learning, data on the participants' characteristics, professional identification and nursing clinical learning environment were collected. Descriptive statistics, including the mean \pm standard deviation, were calculated. The data were analysed by $t$-test, one-way analysis of variance, Pearson's correlation analysis and multiple linear regression.

Results: The results showed that the nursing students' highest professional identity score was in professional cognition (16.07 \pm 2.78$)$. The nursing students' professional identity was significantly related to educational background, willingness to choose the nursing major and school level $(\mathrm{P}<0.05)$. In the clinical learning environment, the students' voluntary selection of the nursing major and teaching methods and interpersonal relationships were most important.

Conclusion: The clinical learning environment and nursing' students personal characteristics are the most important factors influencing the professional identity of nursing students. Based on these results, hospitals should flexibly adapt teaching methods according to students' personal characteristics, improve the professional skills of teachers, and create a good working atmosphere. In addition, faculty members should reform their teaching methods and encourage students to establish good interpersonal relationships to provide more learning opportunities for nursing students and to enhance the recognition of nursing students in the nursing profession.

Keywords: Nursing Students; Clinical Learning Environment; Professional Identity; Clinical Education

\section{Background}

According to the research, the turnover rate of nurses in European countries has reached $12 \% \sim 21 \%{ }^{[1]}$. In 2010 , the turnover rate was $13.9 \%$ in America, $19.9 \%$ in Canada and $36.6 \%$ in Jordan ${ }^{[1]}$. One study showed that the turnover rate is generally highest among nursing students and senior nurses ${ }^{[3]}$. This not only leads to shortages in the nursing workforce but also possibly decreases the quality of care. In addition, the WHO noted that the world will achieve and maintain universal health coverage by 2030 but still lacks nearly 9 million care workers (Word Health Organization, 2019) Therefore, the high turnover rate of nurses and the shortage of nurses have become universal problems worldwide ${ }^{[4]}$, and these problems run counter to the requirements of nursing development ${ }^{[5]}$. As future nurses, nursing students play an important role in the development of nursing. A study has shown that professional identity is an important factor in determining nurses' intention to leave and nursing students' career decisions ${ }^{[6]}$.

Professional identity is an abstract concept that can be theoretically expounded from the aspects of emotion, attitude and values ${ }^{[6]}$. Specifically, the professional identity of nurses refers to the values and attitudes held by nurses that guide their thinking and actions and their interactions with patients ${ }^{[8]}$. The professional identity of nursing students, as prospective nurses, is both the same as and different from that of nurses. For nursing students, professional identity refers to the process of planning their career and confirming their professional role in their current status as nursing students ${ }^{[9]}$. A kind of psychological state determines the professional behaviour of nursing students ${ }^{[10]}$. The cultivation of professional identity will affect the transition of nursing students to professional nurses and their willingness to stay in the nursing profession, which is an important factor in choosing a future career ${ }^{[11]}$. In addition, as nursing students become nurses, professional identity is the basis of their nursing practice and affects their entire career ${ }^{[12]}$. Studies have shown that students with a stronger sense of professional identity are more motivated to work ${ }^{[13]}$ and that nurses with lower levels of professional identity are more likely to quit ${ }^{[13]}$, whereas nurses with a stronger professional identity have a higher retention rate ${ }^{[15]}$. 
The clinical learning environment includes some elements that can be learned in a clinical setting, such as learning opportunities, role building, teaching and patient attitudes, and is an important stage for nursing students ${ }^{[16]}$. Clinical practice provides nursing students with a different learning environment than classroom teaching ${ }^{[17]}$ and creates opportunities for nursing students to learn professional competencies ${ }^{[18]}$. In this environment, nursing students gain experience in emotional and physical interactions ${ }^{[19]}$, which enables them to apply their theoretical knowledge to practice ${ }^{[20]}$, become familiar with clinical work, and deepen their objective understanding of nursing work ${ }^{[21]}$. The environment of clinical practice affects not only the learning outcomes of nursing students but also their views and attitudes towards nursing ${ }^{[22]}$.

Research has shown that clinical practice is the key period for the formation of the professional identity of nursing students ${ }^{[23]}$. Therefore, it is very important to cultivate the professional identity and values of nursing students during clinical practice so that they can become qualified nurses

[24]. Some studies have shown that during clinical practice, nursing students form an objective professional identity and compare imaginary practice with reality by becoming familiar with the working environment ${ }^{[25,26]}$. The professional identity formed by nursing students in practice is closely related to their future career choice ${ }^{[27]}$. In this stage, the components of the clinical learning environment may be important in influencing nursing students' formation of a professional identity. The purpose of this study is to explore the influencing factors of the clinical learning environment on the cultivation of the professional identity of nursing students and to provide references for improving the clinical learning environment of nursing students and enhancing their professional identity.

\section{Method}

\subsection{Study design}

A cross-sectional study was conducted to determine nursing students' professional identity in the clinical learning environment and to examine the association between students' demographic factors, the components of the clinical learning environment and professional identity. All methods were carried out in accordance with relevant guidelines and regulations.

\subsection{Participants}

Convenience sampling was used to select 438 nursing students from 28 different universities who were practising at The Third Xiangya Hospital of Central South University in Hunan Province. The participant inclusion criteria were as follows: 1) all full-time junior college and undergraduate nursing students who practised in the hospital were included, and 2) according to the requirements of the school for completing practice in all departments, the average period was $40.54 \pm 2.70$ weeks, and the average number of departments was $11.39 \pm 1.20$. The participant exclusion criteria were as follows: nursing students who did not complete the requirements for various reasons were excluded.

\subsection{Data collection}

Data were collected from January to March 2019. The questionnaires took approx. 20 min to complete. Those who did not wish to participate read quietly during this time. The information sheet was distributed before participation, and written informed consent was gained prior to the completion of the questionnaires.

Confidentiality and anonymity were maintained by not asking for names and by numbering the questionnaires, with each participant receiving a number on a debriefing sheet. Any student who wanted to withdraw his or her data prior to the commencement of data analysis could do so by contacting the researcher using this number. All data were kept in a locked cupboard and on a password-protected computer to ensure privacy.

\subsection{Measures}

\subsubsection{Demographic information form}

This form was generated by the researcher and consisted of questions concerning gender, age, education, whether the respondent was an only child, residential status, whether the nursing major was voluntarily chosen, and school grades. 
This form included 10 items, with the responses to each item provided on a 5 -point Likert scale $(1=$ never to $5=$ very often $)$. The analysis of the scale yielded a Cronbach's $\alpha$ of 0.71 , and factor analysis yielded an oblique solution ${ }^{[27]}$. Hong Lu translated the professional identification scale into Chinese, and the Cronbach's $\alpha$ of the Chinese version was 0.82 .

\subsubsection{Nursing clinical learning environment evaluation scale}

The responses to each item on this scale were provided on a 5 -point Likert scale ( $1=$ never to $5=$ very often). The form had 30 items divided into 6 dimensions, namely, teaching method, teacher quality, learning opportunities, interpersonal relationships, working atmosphere and organizational support, each of which contained 5 items. The consistency analysis yielded a Cronbach's $\alpha$ of 0.96 . The cumulative contribution rate of the 6 common factors was $73.37 \%$. The correlation coefficients between the dimensions were $0.48 \sim 0.66$. The correlation coefficient between each dimension and the total score was $0.83 \sim 0.86$. The set validity correlation coefficient was $0.56 \sim 0.84$. The correlation coefficient of discriminant validity was $0 \sim 0.46^{[29]}$.

\subsection{Data analysis}

The data were analysed using SPSS version 22.0. Frequency and percentage were used to describe the enumeration and ranking of the data, such as gender, educational background, and whether the respondent was an only child. The mean and standard deviation were used to describe the measurement data in line with the normal distribution, such as age, score of occupational identity and hospital teaching environment evaluation. The $t$-test was used to analyse the professional identity scores of nursing students from the aspects of gender, educational background, whether the respondent was an only child, home address, and whether the choice of the nursing major was voluntary. A one-way analysis of variance (ANOVA) was used to analyse the professional identity scores of nursing students in terms of their school performance and school grades. Pearson's correlation was applied to explore the correlation between dimensions of nursing students' professional identity and dimensions of the clinical learning environment evaluation. The influence of each dimension of the hospital teaching environment evaluation on dimensions of occupational identity was analysed by multiple linear regression. Statistical significance for all analyses was set at $\mathrm{P}<0.05$.

\section{Results}

A total of 398 nursing students participated in this study. Table 1 presents the characteristics of the sample. There were $38(9.5 \%)$ men and 360 $(90.5 \%)$ women. The average age was $20.80 \pm 1.02$. There were 208 nursing students at the diploma level and 190 at the baccalaureate level. The nursing students came from 28 different universities and 3 different levels: there were 208 nursing students from junior colleges, 92 from second-level colleges, and 98 from first-level universities.

The mean score for professional identification was 40.35 out of a maximum score of 50 . In the subscales of professional identification, career cognition had the highest mean score at 16.07, followed by professional impact and professional evaluation (12.68 and 11.46, respectively). The mean score for the nursing clinical learning environment evaluation was 131.86 out of a maximum score of 150 (Table 2 ).

Table 3 shows the relationship between the demographic variables and the dimensions and the total scores of professional identification. According to the $t$-test, there was no significant difference between the professional identification of nursing students of who were not an only child (40.46 \pm 5.34$)$ and nursing students who were an only child $(40.03 \pm 6.00)(\mathrm{P}=0.505)$. However, the professional cognition $(\mathrm{P}<0.001)$ and professional impact $(\mathrm{P}=0.038)$ scores of respondents who were not only children were significantly higher than the scores of those who were only children. The professional identification score of nursing students from rural areas was significantly different from those of nursing students from urban areas $(\mathrm{P}=0.038)$. The scores of the professional identification dimensions were higher for nursing students from rural areas than for those from urban areas. The professional identification score of nursing students who chose the nursing major voluntarily was significantly different from that of nursing students who chose the nursing major involuntarily $(\mathrm{P}<0.001)$. The professional identification score of nursing students with a diploma $(41.13 \pm 4.84)$ was higher than that of nursing students with a baccalaureate education (39.49 \pm 6.07$)$, and the difference was significant ( $\mathrm{P}=0.003)$. In addition, there were significant differences in professional cognition $(\mathrm{P}=0.003)$, professional evaluation $(\mathrm{P} \leqslant 0.001)$ and professional impact $(\mathrm{P}<0.001)$ between nursing students at the diploma and baccalaureate levels, and nursing students with a diploma had significantly higher scores than nursing students at the baccalaureate level. A one-way ANOVA was conducted to examine whether there were differences between school grades and college level for the dimensions and total scores of professional identification. The results showed significant differences $(\mathrm{P}<0.001)$ between the junior college 
(41.12 \pm 4.84$)$, second-level (40.70 \pm 4.93$)$ and first-level (38.37 \pm 6.80$)$ students, and there were also significant differences $(\mathrm{P}<0.001)$ in professional evaluation, professional impact and professional cognition.

Table 4 provides the correlations between the dimensions of the nursing students' professional identification and dimensions of the clinical learning environment evaluation. The results show that the professional identification of the nursing students was positively correlated with teaching methods $(\mathrm{r}=0.36)$ and interpersonal relationships $(\mathrm{r}=0.32, \mathrm{P}<0.01)$. It was also positively correlated with teachers' capacity $(\mathrm{r}=0.34)$, learning opportunities in the clinical learning environment $(\mathrm{r}=0.32)$ and working atmosphere $(\mathrm{r}=0.33, \mathrm{P}<0.05)$. In addition, there was a positive correlation with organizational support $(\mathrm{r}=0.25)$. Therefore, the strength of the professional identification of nursing students is related to teaching methods, teachers' capacity, learning opportunities, working atmosphere, interpersonal relationships and organizational support.

\section{Discussion}

The aim of this study was to explore the correlation between the environmental evaluation and the professional identity of nursing students and to determine the factors influencing the professional identity of nursing students in the clinical learning environment. The professional identity of nursing students is related to whether nursing students are an only child, their grades in school and the practice environment in the hospital.

In this study, nursing students scored the highest in each dimension of professional identity and in the dimension of professional cognition. Therefore, during the internship, nursing students realize the importance of nursing and their own career orientation, which will help them develop their professional identity and reduce the attrition rate of nursing students. The total score and the scores of each dimension of the evaluation of the hospital teaching environment of nursing students were higher than those found in the research results of Chu and $\mathrm{Li}^{[30]}$, indicating that nursing students are relatively satisfied with the hospital teaching environment.

In the analysis of the demographic characteristics, the professional identity of nursing students from the country was obviously higher than that of nursing students from towns. The reason may be that in China, those from rural environments grow up in relatively out-of-the-way areas as a result of the rural economy and poor working conditions; thus, rural nursing students may choose a career more carefully, listen more closely to the opinions of their family, and pay more attention to the stability of the work. This finding indicates that the professional identity of nursing students is related to the environment in which they grew up and lived. In addition, the stronger professional identity of nursing students who chose the nursing major voluntarily may be related to their expectations of and greater interest in the nursing major.

The results of the demographic analysis also show that there are significant differences in the professional identity of nursing students based on the degree and school levels, and there is a certain correlation between these dimensions and the professional identity of nursing students. The research shows that the professional identity of nursing students with a bachelor's degree or above is lower than that of nursing students with a bachelor's degree or below, which is consistent with the research results of $\mathrm{Chu}^{[31]}$. At the same time, the results showed that nursing students with higher school grades had a weaker professional identity. This may be because in China, nursing is considered a low-skilled and low-educated job with low social status that is not respected and valued by society. However, the nursing students with a higher educational level of had higher social expectations and hoped to obtain a higher social status. Thus, because nursing work does not reflect a high social value, the nursing students with a higher educational level had a weaker professional identity. Whether the nursing students voluntarily chose the nursing profession was related to their first impressions of nursing. Compared to nursing students who chose the nursing major involuntarily, those who chose the major voluntarily had more initiative in study and practice, stronger interest in study, and a stronger sense of accomplishment and satisfaction with themselves. Therefore, the voluntary selection of the nursing major is conducive to the formation and development of nursing students' professional identity.

Studies have shown that the professional identity of nursing students is related to the teaching methods of clinical teachers and their own quality ${ }^{[32]}$, learning opportunities in the clinical environment ${ }^{[25]}$, interpersonal relationships ${ }^{[33]}$ and the support of hospital and clinical teachers ${ }^{[18]}$, which is consistent with the results of this study. Studies have shown that the interaction between clinical teachers and nursing students affect the professional identity of nursing students ${ }^{[26]}$. The interaction between clinical teachers and nursing students is most likely to come from the teaching process. The importance of interpersonal relationships in clinical practice for cultivating the professional identity of nursing students is reflected in the following aspects: first, during the internship, a good relationship between nursing students and teachers will enable the students to learn clinical skills more actively to meet their professional demands ${ }^{[34]}$. Second, establishing a good nurse-patient relationship with patients in clinical practice is conducive 
to enhancing the professional confidence of nursing students. Finally, maintaining a good working relationship with other medical staff in the practice department also enables nursing students to experience a harmonious and cooperative relationship in treatment work, experience the work content of other medical workers, and expand their horizons regarding disease treatment. Therefore, in the process of clinical practice, teachers should take the initiative to establish a positive teacher-student relationship with nursing students and encourage nursing students to establish good relationships with patients and other medical staff to enhance the students' sense of belonging to the department, improve their feelings about the nursing profession, and enhance their professional identity.

In addition, this study found that the professional identity of nursing students was related to the working atmosphere of the hospital. First, a positive working atmosphere helped the nursing students maintain a positive and optimistic attitude, which encouraged them to desire a nursing career. Second, organized and planned nursing work and an orderly working atmosphere enabled students to successfully complete the internship task and were conducive to enhancing the job satisfaction of nursing students. Finally, the high-quality nursing service of clinical nurses improved patients' satisfaction and understanding of nurses' work and enhanced nursing students' pride in participating in nursing work. The results show that teaching hospitals should provide more learning opportunities for nursing students, broaden their professional horizons and stimulate their love of nursing to create a good working atmosphere; provide a safe and harmonious internship environment for nursing students; and increase their expectations for their future careers. In addition, clinical teachers should strive to improve their own quality, reform clinical teaching methods, reasonably allocate treatment tasks and teaching time, consolidate the knowledge and skills of nursing students, and strengthen the professional identity of nursing students.

\section{Summary}

This study determined the influencing factors of nursing students' professional identity in the hospital practice teaching environment. Among the influencing factors, whether nursing students chose the nursing major voluntarily, interpersonal relationships in the practice environment and teaching methods play an important role in influencing nursing students' professional identity. Teaching hospitals can improve the quality of clinical teachers, innovate teaching methods, create a good hospital working atmosphere, and provide a good practice environment for nursing students. During clinical practice, teachers should take the initiative to communicate with nursing students, encourage them to establish good interpersonal relationships, provide more learning opportunities and improve their professional potential. Therefore, researchers should study ways to change the clinical learning environment to improve the professional identity of nursing students and provide more nursing talent for future nursing workforce.

\section{Study Limitations}

Although this study focused mainly on the factors influencing nursing students' professional identity in the clinical learning environment, there are some limitations. The data in this study are from only one region, and the source area of the research objects is too limited to generalize this study. In addition, the understanding of the life of nursing students in this study is limited to quantitative studies. The method of hybrid research should be used to compensate for the shortage of quantitative research through qualitative research. However, the results of this study have a certain reference value for changing the clinical learning environment and promoting the cultivation of the professional identity of nursing students.

\section{Ethics approval and consent to participate}

Ethical approval was obtained from the Institutional Review Committee of The Third Xiangya Hospital of Central South University (No:2020-S003). All participants were informed about the purpose and process of this study. Both verbal and written explanations of the survey and the purpose of the research were provided to the nursing students. Participation in the study was voluntary. Students had the right to withdraw from the study without adverse effects on their academic standing. All of the information collected was maintained in strict confidence. All participants provided written consent by filling in the written questionnaires.

\section{Consent for publication}

Not applicable.

\section{Availability of data and materials}


All data generated or analysed during this study are included in this published article and its supplementary information files.

\section{Competing interests}

This manuscript maintains no competing financial interest declaration from any person or organization, or non-financial competing interests such as political, personal, religious, ideological, academic, intellectual, commercial or any other.

\section{Founding}

The cost of data collection for this research was funded by the Natural Science Foundation of Hunan Province (Grant Reference Number: 2018JJ2615), the Research Project on Teaching Reform in Colleges and Universities in Hunan Province (Grant Reference Number: 2017jy89), the Key Laboratory of Nursing Science in Hunan Province (Grant Reference Number: 2017TP1004) and the Hunan Provincial Key Research and Development Program Subproject (Grant Reference Number:2019SK2141).

\section{Authors' contributions}

We contributed to the drafting of proposal, design, analysis and interpretation of the data, and manuscript preparation. Lihong Zeng and Hui Huang were also involved in data analysis as well as drafting and revising this research paper. Qirong Chen were involved in the interpretation of the data and contributed to data analysis. All authors were informed and gave the go ahead to publish the work. We agrees to be held accountable for all aspects of the work hence any questions related to the accuracy or integrity of the work should be directed to We. The authors declare that this manuscript has not been presented to any other journal for publication. All authors read and approved the final manuscript.

\section{Acknowledgements}

We would like to extend our sincere gratitude to the data collectors, participants, hospitals directors, and faculty members for their great assistance and cooperation.

\section{References}

[1] Roche M A, Duffield C M, Homer C, et al. The rate and cost of nurse turnover in Australia[J]. Collegian, 2015， 22(4): 353-358.

[2] Li Y, Jones C B. A literature review of nursing turnover costs[J]. J Nurs Manag, 2013， 21(3): 405-418.

[3] Gambino K M. Motivation for entry, occupational commitment and intent to remain: a survey regarding Registered Nurse retention[J]. J Adv Nurs, 2010, 66(11): 2532-2541

[4] Lu H, While A E, Barriball K L. Job satisfaction and its related factors: a questionnaire survey of hospital nurses in Mainland China[J]. Int J Nurs Stud, 2007, 44(4): 574-588.

[5] Wu C, Palmer M H, Sha K. Professional identity and its influencing factors of first-year post-associate degree baccalaureate nursing students: A cross-sectional study[J]. Nurse Education Today, 2020, 84.

[6] Sabanciogullari S, Dogan S. Relationship between job satisfaction, professional identity and intention to leave the profession among nurses in Turkey[J]. J Nurs Manag, 2015, 23(8): 1076-1085.

[7] Ferrell C, Christian R, Rachel M. Registered nurse experiences of nursing professional identity: a qualitative systematic review protocol[J]. JBI Database System Rev Implement Rep， 2017， 15(12): 2866-2870.

[8] Wang Y, Zhang B. IMPACT OF PERSONALITY TRAIT AND PROFESSIONAL IDENTITY ON WORK-RELATED DEPRESSION, ANXIETY AND IRRITATION AMONG CHINESE NURSES[J]. Southeast Asian J Trop Med Public Health， 2017， 48(2): 447-454.

[9] Ohlen J, Segesten K. The professional identity of the nurse: concept analysis and development[J]. J Adv Nurs, 1998, 28(4): $720-727$.

[10] Kirpal S. Work identities of nurses: Between caring and efficiency demands[J]. Career Development International, 2004, 9(3): 274-304.

[11] Browne C, Wall P, Batt S, et al. Understanding perceptions of nursing professional identity in students entering an Australian undergraduate nursing degree[J]. Nurse Educ Pract, 2018，32: 90-96.

[12] Cook P R, Cullen J A. Caring as an imperative for nursing education[J]. Nurs Educ Perspect, 2003， 24(4): 192-197.

[13] Koo H Y, Kim E J. Vocational Identity and Ego Identity Status in Korean Nursing Students[J]. Asian Nurs Res (Korean Soc Nurs Sci), 2016 , $10(1)$ : 68-74.

[14] Worthington M, Salamonson Y, Weaver R, et al. Predictive validity of the Macleod Clark Professional Identity Scale for undergraduate nursing students[J]. 
Nurse Educ Today, 2013, 33(3): 187-191.

[15] Galles J A, Lenz J G. Relationships Among Career Thoughts, Vocational Identity, and Calling: Implications for Practice[J]. Career Development Quarterly, 2013, 61(3): 240-248.

[16] Moscaritolo L M. Interventional strategies to decrease nursing student anxiety in the clinical learning environment[J]. J Nurs Educ, 2009, 48(1): 17-23.

[17] Salamonson Y, Everett B, Halcomb E, et al. Unravelling the complexities of nursing students' feedback on the clinical learning environment: a mixed methods approach[J]. Nurse Educ Today, 2015, 35(1): 206-211.

[18] Carlson S, Kotze W J, van Rooyen D. Accompaniment needs of first year nursing students in the clinical learning environment[J]. Curationis, 2003, 26(2): $30-39$.

[19] Papastavrou E, Dimitriadou M, Tsangari H. Psychometric Testing of the Greek Version of the Clinical Learning Environment-Teacher (CLES+T)[J]. Glob J Health Sci, 2015, 8(5): 59-71.

[20] Ramsbotham J, Dinh H, Truong H, et al. Evaluating the learning environment of nursing students: A multisite cross-sectional study[J]. Nurse Education Today, 2019, 79 .

[21] Sun L, Gao Y, Yang J, et al. The impact of professional identity on role stress in nursing students: A cross-sectional study[J]. Int J Nurs Stud, 2016, 63: 1-8.

[22] Flott E A, Linden L. The clinical learning environment in nursing education: a concept analysis[J]. Journal of Advanced Nursing, 2016 , $72(3): 501$.

[23] Killam L A, Heerschap C. Challenges to student learning in the clinical setting: a qualitative descriptive study[J]. Nurse Educ Today, 2013, 33(6): 684-691.

[24] Yousefy A, Yazdannik A, Mohammadi S. Exploring the environment of clinical baccalaureate nursing students' education in Iran; A qualitative descriptive study[J]. Nurse Educ Today, 2015, 35(12): 1295-1300.

[25] Arreciado M A, Isla P M. Theory and practice in the construction of professional identity in nursing students: a qualitative study[J]. Nurse Educ Today, 2015, 35(7): 859-863.

[26] Clements A J, Kinman G, Leggetter S, et al. Exploring commitment, professional identity, and support for student nurses[J]. Nurse Educ Pract, 2016, 16(1): $20-26$.

[27] Baldwin A, Mills J, Birks M, et al. Reconciling professional identity: A grounded theory of nurse academics' role modelling for undergraduate students[J]. Nurse Educ Today, 2017, 59: 1-5.

[28] Brown R, Condor S, Mathews A, et al. Explaining intergroup differentiation in an industrial organization[J]. Journal of Occupational Psychology, 2011, 59(4): $273-286$.

[29] Laxian H, Yanxiang C, Xiuyun L. Preparation and reliability and validity test of environmental assessment scale for nursing clinical practice[J]. Journal of nursing, 2011, 26(09): 1-4.

[30] Yanxiang C, Xiuyun L. Investigation and analysis of nursing students' satisfaction with clinical practice environment[J]. Chinese nursing managment, 2011, 11(10): 37-40.

[31] Jing C. Research on professional identity of nursing students during their internship and construction of promotion strategies[D]. The Second Military Medical University, 2014.

[32] Brown J, Stevens J, Kermode S. Supporting student nurse professionalisation: the role of the clinical teacher[J]. Nurse Educ Today, 2012, 32(5): 606-610.

[33] Sabatino L, Rocco G, Stievano A, et al. Perceptions of Italian student nurses of the concept of professional respect during their clinical practice learning experience[J]. Nurse Educ Pract, 2015, 15(4): 314-320.

[34] Stella K, BCE. Clinical supervision and support: Perspectives of undergraduate nursing students on their clinical learning environment in Malawi.[J]. Curationis, 2019, 42(1). 
Table 1

Characteristics of the sample

\begin{tabular}{|c|c|}
\hline Variable & $\mathrm{N}(\%) /$ Mean $\pm \mathrm{SD}$ \\
\hline \multicolumn{2}{|l|}{ Gender } \\
\hline Male & $38(9.5)$ \\
\hline Female & $360(90.5)$ \\
\hline Age & $20.80 \pm 1.02$ \\
\hline \multicolumn{2}{|l|}{ Education } \\
\hline Diploma & $208(52.3)$ \\
\hline Baccalaureate level & $190(47.7)$ \\
\hline \multicolumn{2}{|l|}{ Only child in family } \\
\hline Yes & $105(26.4)$ \\
\hline No & $293(73.6)$ \\
\hline \multicolumn{2}{|l|}{ Residential status } \\
\hline Rural & $187(47.0)$ \\
\hline Urban & 211（53.0） \\
\hline \multicolumn{2}{|c|}{$\begin{array}{l}\text { Voluntary choice of nursing } \\
\text { major }\end{array}$} \\
\hline Yes & $276(69.3)$ \\
\hline No & $122(30.7)$ \\
\hline \multicolumn{2}{|l|}{ Grades in school } \\
\hline Excellent & $197(49.5)$ \\
\hline Medium & $188(47.2)$ \\
\hline Poor & $13(3.3)$ \\
\hline \multicolumn{2}{|l|}{ Level of college } \\
\hline Junior college & $208(52.3)$ \\
\hline Second level & $92(23.1)$ \\
\hline First level & $98(24.6)$ \\
\hline
\end{tabular}




\section{Table 2}

Level of professional identification and nursing clinical learning environment evaluation

\begin{tabular}{|c|c|c|}
\hline Scale & Categories & Mean \pm SD \\
\hline \multirow[t]{4}{*}{ Professional identification } & Professional evaluation & $11.46 \pm 2.55$ \\
\hline & Professional impact & $12.68 \pm 2.04$ \\
\hline & Professional cognition & $16.07 \pm 2.78$ \\
\hline & Total & $40.35 \pm 5.51$ \\
\hline \multirow{7}{*}{$\begin{array}{l}\text { Nursing clinical learning } \\
\text { environment evaluation }\end{array}$} & Learning opportunities & $21.26 \pm 3.74$ \\
\hline & Organizational support & $21.48 \pm 4.35$ \\
\hline & Teaching method & $21.71 \pm 3.34$ \\
\hline & Interpersonal relationships & $22.27 \pm 3.19$ \\
\hline & Working atmosphere & $22.46 \pm 3.27$ \\
\hline & Teacher capacity & $22.68 \pm 2.90$ \\
\hline & Total & $131.86 \pm 18.08$ \\
\hline
\end{tabular}




\section{Table 3}

The relationship between the demographic characteristics and the dimension and total scores of professional identification

\begin{tabular}{|c|c|c|c|c|c|c|c|c|c|c|c|c|}
\hline \multirow{2}{*}{$\begin{array}{l}\text { Demographic } \\
\text { characteristic }\end{array}$} & \multicolumn{3}{|c|}{ Professional identification } & \multicolumn{3}{|c|}{ Professional cognition } & \multicolumn{3}{|c|}{ Professional evaluation } & \multicolumn{3}{|c|}{ Professional impact } \\
\hline & Mean \pm SD & $\mathrm{t} / \mathrm{F}$ & $\mathrm{P}$ & Mean \pm SD & $t / F$ & $\mathrm{P}$ & Mean \pm SD & $\mathrm{t} / \mathrm{F}$ & $\mathrm{P}$ & Mean \pm SD & $t / F$ & $P$ \\
\hline \multicolumn{13}{|l|}{ Gender } \\
\hline \multirow[t]{2}{*}{ Male } & $40.74 \pm 5.32$ & & & $11.61 \pm 2.94$ & & & $12.55 \pm 1.98$ & & & $16.00 \pm 2.58$ & & \\
\hline & & 0.458 & 0.647 & & 0.363 & 0.717 & & 0.416 & 0.678 & & 0.17 & 0.865 \\
\hline Female & $40.31 \pm 5.54$ & & & $11.45 \pm 2.51$ & & & $12.70 \pm 2.05$ & & & $16.08 \pm 2.80$ & & \\
\hline \multicolumn{13}{|l|}{ Education } \\
\hline \multirow[t]{2}{*}{ Diploma } & $41.13 \pm 4.84$ & & & $11.82 \pm 2.38$ & & & $13.04 \pm 2.05$ & & & $16.71 \pm 2.43$ & & \\
\hline & & 2.975 & 0.003 & & 2.976 & 0.003 & & 3.695 & $<0.001$ & & 4.901 & $<0.001$ \\
\hline Baccalaureate level & $39.49 \pm 6.07$ & & & $11.07 \pm 2.67$ & & & $12.29 \pm 1.95$ & & & $15.38 \pm 2.96$ & & \\
\hline \multicolumn{13}{|l|}{ Only child in family } \\
\hline \multirow[t]{2}{*}{ Yes } & $40.03 \pm 6.00$ & & & $10.66 \pm 3.17$ & & & $12.58 \pm 2.08$ & & & $15.59 \pm 3.08$ & & \\
\hline & & 0.668 & 0.505 & & 3.837 & $<0.001$ & & 0.6 & 0.549 & & 2.083 & 0.038 \\
\hline No & $40.46 \pm 5.34$ & & & $11.75 \pm 2.22$ & & & $12.72 \pm 2.02$ & & & $16.25 \pm 2.65$ & & \\
\hline \multicolumn{13}{|l|}{ Residential status } \\
\hline \multirow[t]{2}{*}{ Rural } & $40.96 \pm 5.39$ & & & $11.84 \pm 2.36$ & & & $12.96 \pm 1.70$ & & & $16.40 \pm 2.49$ & & \\
\hline & & 2.106 & 0.036 & & 2.804 & 0.005 & & 2.541 & 0.011 & & 2,231 & 0.026 \\
\hline Urban & $39.80 \pm 5.58$ & & & $11.13 \pm 2.66$ & & & $12.44 \pm 2.27$ & & & $15.78 \pm 2.98$ & & \\
\hline \multicolumn{13}{|l|}{$\begin{array}{l}\text { Voluntary choice of } \\
\text { nursing major }\end{array}$} \\
\hline \multirow[t]{2}{*}{ Yes } & $41.36 \pm 4.82$ & & & $11.86 \pm 2.47$ & & & $13.07 \pm 1.89$ & & & $16.58 \pm 2.60$ & & \\
\hline & & 5.766 & $<0.001$ & & 4.748 & $<0.001$ & & 6.035 & $<0.001$ & & 5.734 & $<0.001$ \\
\hline No & $38.04 \pm 6.26$ & & & $10.57 \pm 2.50$ & & & $11.79 \pm 2.07$ & & & $14.91 \pm 2.83$ & & \\
\hline \multicolumn{13}{|l|}{ Grades in school } \\
\hline Excellent & $40.46 \pm 5.40$ & & & $11.79 \pm 2.43$ & & & $12.70 \pm 2.08$ & & & $16.30 \pm 2.73$ & & \\
\hline Medium & $40.40 \pm 5.64$ & 1.389 & 0.251 & $11.13 \pm 2.66$ & 3.33 & 0.037 & $12.72 \pm 2.00$ & 1.142 & 0.32 & $15.90 \pm 2.81$ & 1.899 & 0.151 \\
\hline Poor & $37.85 \pm 5.06$ & & & $11.31 \pm 2.55$ & & & $11.85 \pm 1.91$ & & & $15.08 \pm 2.72$ & & \\
\hline \multicolumn{13}{|l|}{ Level of college } \\
\hline Junior college & $41.12 \pm 4.84$ & & & $11.82 \pm 2.38$ & & & $13.04 \pm 2.05$ & & & $16.71 \pm 2.43$ & & \\
\hline Second level & $40.70 \pm 4.93$ & 8.909 & $<0.001$ & $11.56 \pm 2.69$ & 8.003 & $<0.001$ & $12.64 \pm 1.88$ & 9.593 & $<0.001$ & $15.91 \pm 2.82$ & 15.74 & $<0.001$ \\
\hline First level & $38.37 \pm 6.80$ & & & $10.60 \pm 2.58$ & & & $11.97 \pm 1.97$ & & & $14.88 \pm 3.02$ & & \\
\hline
\end{tabular}




\section{Table 4}

The correlations between the dimensions of nursing students' professional identification and the dimensions of the clinical learning environment evaluation

\begin{tabular}{|c|c|c|c|c|c|c|c|c|}
\hline & $\begin{array}{l}\text { Professional } \\
\text { identification }\end{array}$ & $\begin{array}{l}\text { Teaching } \\
\text { method }\end{array}$ & $\begin{array}{l}\text { Teacher } \\
\text { capacity }\end{array}$ & $\begin{array}{l}\text { Learning } \\
\text { opportunities }\end{array}$ & $\begin{array}{l}\text { Interpersonal } \\
\text { relationships }\end{array}$ & $\begin{array}{l}\text { Working } \\
\text { atmosphere }\end{array}$ & $\begin{array}{l}\text { Organizational } \\
\text { support }\end{array}$ & $\begin{array}{l}\text { Clinical learning } \\
\text { environment } \\
\text { evaluation }\end{array}$ \\
\hline $\begin{array}{l}\text { Professional } \\
\text { identification }\end{array}$ & 1 & & & & & & & \\
\hline Teaching method & $0.36^{* *}$ & 1 & & & & & & \\
\hline Teacher capacity & $0.34 *$ & $0.77 * *$ & 1 & & & & & \\
\hline Learning opportunities & $0.32 *$ & $0.71 * *$ & $0.70 * *$ & 1 & & & & \\
\hline $\begin{array}{l}\text { Interpersonal } \\
\text { relationships }\end{array}$ & $0.32 * *$ & $0.61 * *$ & $0.73 * *$ & $0.73 * *$ & 1 & & & \\
\hline Working atmosphere & $0.33 * *$ & $0.68 * *$ & $0.76^{* *}$ & $0.74 * *$ & $0.85 * *$ & 1 & & \\
\hline Organizational support & $0.25 * *$ & $0.62 * *$ & $0.62 * *$ & $0.72 * *$ & $0.70 * *$ & $0.72 * *$ & 1 & \\
\hline $\begin{array}{l}\text { Clinical learning } \\
\text { environment evaluation }\end{array}$ & $0.36^{* *}$ & $0.84 * *$ & $0.86^{* *}$ & $0.89 * *$ & $0.88 * *$ & $0.90 * *$ & $0.86^{* *}$ & 1 \\
\hline
\end{tabular}

**. The correlation was significant at the 0.01 (two-tailed) level. 


\section{Supplementary Files}

This is a list of supplementary files associated with this preprint. Click to download.

- Tablepage.pdf 